\title{
Malondialdehyde levels are higher and glutathione levels are lower in preeclampsia than in normal pregnancies
}

\author{
Subandrate*, Mia Esta Poetri Afdal Faisal**, Nurul Windi Anggraini***, \\ and Sadakata Sinulingga ${ }^{\dagger}$
}

\begin{abstract}
BACKGROUND
Maternal mortality rate is still a health problem in Indonesia. One major contributor to maternal mortality rate in Indonesia is preeclampsia. One widely accepted theory is that preeclampsia is caused by oxidative stress. Placental hypoxia or ischemia among preeclampsia patients is thought to be the cause of the formation of free radicals such as malondialdehyde (MDA), which decreases endogenous antioxidants such as glutathione (GSH). This study aims to ascertain the difference in plasma malondialdehyde and glutathione levels between healthy and preeclamptic pregnant women.
\end{abstract}

\section{METHODS}

This was an observational analytic study of cross sectional design. Research subjects were 30 normal (healthy) pregnant women (NP), and 30 pre-eclamptic pregnant (PE) women. The measurement of plasma MDA and GSH levels was done at the Biochemistry and Molecular Biology laboratories, Faculty of Medicine, Sriwijaya University using Sigma-Aldrich MDA and GSH assay kits. Mann Whitney test was used to analyze the data.

\section{RESULTS}

Subjects aged $>35$ years, with age of gestation $>35$ weeks and multipara was significantly higher in the PE group compared to the NP group $(\mathrm{p}=0.016$; $\mathrm{p}=0.01$ and $\mathrm{p}=0.36$; respectively). MDA level was significantly higher in the PE group than in the NP group ( $p=0.002)$. In contrast, GSH level was significantly lower in the PE group than in the NP group $(\mathrm{p}=0.003)$.

\section{CONCLUSION}

MDA and GSH may reflect vascular complications of PE, and the ensuing increases in lipid peroxidation may play important pathogenic roles.

Keywords: Free radical, GSH, normal pregnant, MDA, preeclampsia
*Department of Biochemistry and Medical Chemistry, Faculty of Medicine, Sriwijaya University **Medical Study Program, Faculty of Medicine, Sriwijaya University ***Medical Study Program, Faculty of Medicine, Sriwijaya University 'Department of Biochemistry and Medical Chemistry, Faculty of Medicine, Sriwijaya University

\section{Correspondence:}

Subandrate

Department of Biochemistry and Medical Chemistry,

Faculty of Medicine,

Sriwijaya University

Jl. Dr. M. Ali Komp. RSMH KM 3,5

Palembang Sumsel 30126

Phone and fax: $+62711-373438$

Email: subandrate@unsri.ac.id

Date of first submission, June 20, 2017

Date of final revised submission,

November 8, 2017

Date of acceptance, November 10, 2017

This open access article is distributed under a Creative Commons AttributionNon Commercial-Share Alike 4.0

International License

Cite this article as: Subandrate, Faisal MEAF, Anggraini NW, et al. Malondialdehyde levels are higher and glutathione levels are lower in preeclampsia than in normal pregnancies. Univ Med 2017;36:179-86. doi: 10.18051/UnivMed.2017.v36.179186 


\section{INTRODUCTION}

The government and the obstetrics experts and personnel in Indonesia are always cooperating to improve the quality of public health care services. One of the parameters of success in obstetric service is the maternal mortality rate (MMR), as one of the sustainable development goals (SDG) of the WHO, i.e. a decrease in MMR below 70 per 100,000 live births, to be achieved up to the year 2030. ${ }^{(1)}$

The results of the Indonesian Basic Health Survey (Survei Dasar Kesehatan Indonesia, SDKI) in 2012 showed that the Indonesian MMR actually increased to 359 per 100,000 live births. ${ }^{(2)}$ One of the largest contributors to the MMR in developing countries such as Indonesia is preeclampsia, in addition to eclampsia, bleeding and sepsis. ${ }^{(1,3)}$ The MMR of South Sumatra is still according to the results of the Indonesian National Socio-economic Survey (Survei Sosial Ekonomi Nasional, SUSENAS) for the year 2005, i.e. 262 per 1000 live births, ${ }^{(2)}$ whereas the target MMR of the WHO Millennium Development Goals (MDGs) for 2015 is $102 / 100.000$ live births. ${ }^{(1,3)}$

Preeclampsia is a syndrome encountered from the twentieth week of pregnancy up to 48 hours after delivery, and is characterized by hypertension and proteinuria. ${ }^{(4)}$ The US National High Blood Pressure Education Program Working Group classifies preeclampsia as one of the categories of hypertension in pregnancy and uses the criterion of an increase in blood pressure of $>140 / 90 \mathrm{mmHg}$ with proteinuria of $>300 \mathrm{mg}$ in 24-hour urine. ${ }^{(4,5)}$ Preeclampsia is "the disease of theories", because the initial cause of preeclampsia is not yet known with certainty. The ischemic placenta theory is one of the hypotheses on the etiology of preeclampsia that is accepted by the experts. ${ }^{(4)}$ The ischemic placenta theory explains that failure of trophoblastic invasion into the spiral arteries leads to abnormalities of the uteroplacental blood supply so that there is diminished uteroplacental perfusion that ultimately causes the ischemic-hypoxic placenta to produce an excess of free radicals in the maternal circulation. ${ }^{(4,6,7)}$

The increase in free radicals drastically shifts the normal condition to oxidative stress, in which the amount of free radicals in the body exceeds the neutralizing capacity of the body. Oxidative stress is toxic and damages lipids, proteins, and DNA. ${ }^{(7-9)}$ Oxidation of lipids by free radicals produces malondialdehyde (MDA). To date MDA is considered to be a good in-vivo oxidative stress marker. ${ }^{(8,10)}$ Oxidative stress actually does not occur if there is a balance between oxidants and antioxidants. One of the antioxidants that plays a role in quenching free radicals is reduced glutathione (GSH) that acts by preventing the formation of oxygen radicals. ${ }^{(11,12)}$ Oxidative stress in a pregnancy complicated by preeclampsia is thought to cause an increase in MDA concentration and a reduction in $\mathrm{GSH}$ concentration. This results in damage to the vascular endothelium and vital target organs. ${ }^{(12)}$

Several studies have demonstrated the occurrence of oxidative stress in placentas of patients with preeclampsia. ${ }^{(12-14)}$ The study conducted by Chandra et al. ${ }^{(11)}$ shows that mean MDA increases and mean GSH decreases significantly in preeclampsia, as compared with normal pregnancy. The study of Suhail et al. ${ }^{(12)}$ shows that increased MDA concentration and decreased GSH concentration in preeclampsia causes fragility of the red blood cells. These studies differ from those carried out by Bowen et al. ${ }^{(15)}$ and Dordevic et al. ${ }^{(16)}$ Bowen et al. ${ }^{(15)}$ state that there is no reduction in antioxidants or an increase in lipid peroxidation (MDA) in preeclampsia as compared with normal pregnancy. The study carried out by Dordević et al. ${ }^{16)}$ also shows that there is no difference in antioxidant (GSH) concentration between women with normal pregnancy and those with preeclampsia.

Since the results of these studies are still inconsistent concerning the differences in MDA and GSH concentrations between normal pregnancies and preeclampsia, further studies 
are necessary. The aim of the present study was to determine the differences in plasma GSH and MDA concentrations between women with preeclamptic pregnancy (PE) and those with normal pregnancy (NP).

\section{METHODS}

\section{Research design}

The present study was an observational analytic study of cross sectional design that was carried out in the Department of Obstetrics and Gynecology of Muhammadiyah Palembang Hospital, from September 2016 to February 2017.

\section{Study subjects}

The study subjects were all pregnant women with preeclampsia and normal pregnant women who came for treatment or were hospitalized in the Department of Obstetrics and Gynecology, Muhammadiyah Palembang Hospital, who met the inclusion criteria and did not have the exclusion criteria of the study. The inclusion criteria were pregnant women aged 1840 years with a single live fetus, age of gestation of 20-40 weeks, and diagnosed as preeclampsia or normal pregnancy. The exclusion criteria were pregnant women with complications of other diseases (renal disorders, chronic hypertension, diseases of the liver, antepartum hemorrhage, heart disease and diabetes mellitus), smokers and alcohol consumers.

\section{Sample size determination}

The sample size was determined with the formula for two population means, i.e. $\mathrm{n}_{1}=\mathrm{n}_{2}=2\left[\left(\mathrm{Z}_{\alpha}+\mathrm{Z}_{\beta}\right) \mathrm{S} /\left(\mathrm{x}_{1}-\mathrm{x}_{2}\right)\right]^{2}$, where the value of $Z_{\alpha}$ is $5 \%$, the value of $Z_{\beta}$ is $10 \%$, the value of $S=$ $0.71 \mathrm{nmol} / \mathrm{mL}$, and the value of $\times 1-x 2=0.54$ $\mathrm{nmol} / \mathrm{mL} .^{(11)}$ The resulting sample size was 30 pregnant patients with preeclampsia and 30 normal pregnant patients. The selection of the sample for this study was by non-random consecutive sampling. In which all subjects who met the study criteria were selected consecutively until the sample size was reached. The willingness of the patients to participate in the study was given by informed consent after the patients received clarification on the benefits and discomforts to the patients who participated in this study.

\section{Data collection}

Data collection was carried out by directly interviewing the patients and by looking at the data in the medical records using a check list with the patient's name (initials), age, first day of the last menstrual period (LMP), age of pregnancy, parity, and diagnosis. The diagnosis of pregnancy with preeclampsia had been established by specialists in obstetrics and gynecology for those patients who met the conditions of age of pregnancy of more than 20 weeks, systolic blood pressure above $140 \mathrm{mmHg}$ or diastolic blood pressure above $90 \mathrm{mmHg}$, and proteinuria. ${ }^{(4)}$

\section{Laboratory analysis}

Collection of laboratory samples was performed by drawing $3 \mathrm{ml}$ of blood from the median cubital vein of the study subject and placing the blood sample in an ethylene-diamine tetra-acetic acid (EDTA)-containing blood collecting tube. The collected blood sample was centrifuged for 10 minutes at $600 \mathrm{~g}$, and part of the separated plasma was taken and placed in a labeled tube and stored at $-20^{\circ} \mathrm{C}$ before determination of the MDA and GSH concentrations. Determination of the plasma MDA and GSH concentrations was carried out in the Biochemistry and Molecular Biology laboratories, Faculty of Medicine, Sriwijaya University, using the procedures of the SigmaAldrich MDA and GSH assay kits.

The plasma MDA concentration was determined biochemically using the SigmaAldrich MDA assay kit. A volume of $10 \mu \mathrm{l}$ plasma was mixed with $500 \mu 1 \mathrm{H}_{2} \mathrm{SO}_{4} 42 \mathrm{mM}$ and $125 \mu 1$ phosphotungstic acid. The mixture was vortexed and incubated at room temperature for 5 minutes, then centrifuged at 
$13,000 \mathrm{~g}$ for 3 minutes. The precipitate was taken and resuspended in a solution of butylated hydroxytoluene (BHT) in distilled water up to $200 \mu 1$. After that, $600 \mu 1$ of thiobarbituric acid (TBA) solution was added to the suspension and incubated at $95^{\circ} \mathrm{C}$ for 60 minutes. The mixture was cooled in ice water for 10 minutes. A volume of $200 \mu 1$ of the mixture was placed on a 96well plate and its absorbance read with a spectrophotometer at a wavelength of $532 \mathrm{~nm}$. The MDA concentration in $\mathrm{nmol} / \mu \mathrm{l}$ was then determined using the MDA standard curve.

The plasma GSH concentration was determined biochemically using the SigmaAldrich GSH assay kit. A volume of $200 \mu 1$ plasma was mixed with $200 \mu \mathrm{lSSA} 5 \%$. The mixture was vortexed and left for 10 minutes at $2-8{ }^{\circ} \mathrm{C}$. After that, the mixture was centrifuged at $10,000 \mathrm{~g}$ for 10 minutes. Then, a volume of $10 \mu 1$ of supernatant was taken and mixed with $150 \mu 1$ Working Mixture in a 96-well plate. The mixture was incubated for 5 minutes at room temperature then $50 \mu 1$ of NADPH solution was added. Then the absorbance was measured by spectrophotometer at a wavelength of $412 \mathrm{~nm}$. The GSH concentration in $\mu \mathrm{mol} / \mathrm{ml}$ was then determined using the GSH standard curve.

\section{Statistical analysis}

The statistical analyses used were the Mann-Whitney test and the chi square test. Significancy was considered for $\mathrm{p}<0.05$.

\section{Ethical clearance}

This study was carried out after obtaining ethical clearance from the Unit on Bioethics and Humanities Unit, Faculty of Medicine, Sriwijaya University/RSMH Palembang, under nos. 194 and 324/kepkrsmhfkunsri/2016.

\section{RESULTS}

The age of the pregnant women who were the study subjects varied from 18 to 40 years. In the PE group the number of subjects aged $>$ 35 years was $7(23.3 \%)$, which was significantly higher than the number of NP subjects of 2 $(6.7 \%)(p=0.016)$. Mean age of gestation for all study subjects was $33.07 \pm 5.89$ weeks. The number of subjects with a pregnancy of $>33$ weeks was significantly greater in the PE group [26 (86.7\%)] as compared with that in the NP group $[9(30.0 \%)](p=0.001)$. Mean parity of all study subjects was $1.13 \pm 1.00$. The number of multipara were significantly higher in the PE group $[10(33.3 \%)]$ as compared with that in the NP group [5 (16.7\%)] $(\mathrm{p}=0.036)$.

The demographic characteristics and clinical features of the study subjects can be seen in Table 1.

In the present study the median, minimum, and maximum plasma MDA concentration in the NP group were $18.29,8.80$ and $21.93 \mathrm{nmol} / \mu \mathrm{l}$, respectively. These values were significantly lower than those in the PE group, i.e. 20.66, 7.19

Table 1. Demographic and clinical features of the study groups

\begin{tabular}{lccc}
\hline Variable & $\begin{array}{c}\text { Normal pregnancy } \\
(\mathbf{n}=\mathbf{3 0})\end{array}$ & $\begin{array}{c}\text { Preeclampsia } \\
(\mathbf{n}=\mathbf{3 0})\end{array}$ & p value \\
\hline Age (years) & $4(13.3)$ & $0(0.0)$ & 0.016 \\
$<20$ & $24(80.0)$ & $23(76.7)$ & $7(23.3)$ \\
$20-35$ & $2(6.7)$ & & 0.001 \\
$>35$ & & $0(0.0)$ & \\
Age of gestation (weeks) & $12(40.0)$ & $4(13.3)$ & 0.036 \\
$20-28$ & $9(30.0)$ & $26(86.7)$ & \\
$28-33$ & $9(30.0)$ & $6(20.0)$ & \\
$>33$ & & $14(46.7)$ & $10(33.3)$ \\
Parity & $10(33.3)$ & $15(50.0)$ & \\
Nullipara & $5(16.7)$ & & \\
Primipara &
\end{tabular}

*Chi square test, significant if $\mathrm{p}<0.05$; Data are presented as $\mathrm{n}(\%)$ 
Table 2. Plasma MDA and GSH concentrations in normal pregnancy and preeclampsia

\begin{tabular}{lccc}
\hline Variable & $\begin{array}{c}\text { Normal pregnancy } \\
(\mathbf{n = 3 0 )}\end{array}$ & $\begin{array}{c}\text { Preeclampsia } \\
(\mathbf{n = 3 0 )}\end{array}$ & p value \\
\hline $\begin{array}{l}\text { MDA (nmol/ } \mu \mathrm{l}) \\
\text { Median }\end{array}$ & 18.29 & & 0.002 \\
$\quad$ Min-Max) & $(8.80-21.93)$ & $(7.19-49.98)$ & \\
GSH $(\mu \mathrm{mol} / \mathrm{ml})$ & 11.46 & 10.15 & 0.003 \\
Median & $(9.74-16.40)$ & $(7.34-11.96)$ & \\
$\quad$ Min-Max $)$ & & & \\
\hline
\end{tabular}

*MannWhitney test, significant if $\mathrm{p}<0.05$, data presented as median range (minimum - maximum)

and $49.98 \mathrm{nmol} / \mu \mathrm{l}$, respectively $(\mathrm{p}<0.002)$. The median, minimum, and maximum plasma GSH concentration in the NP group were 11.46, 9.74 and $16.40 \mu \mathrm{mol} / \mathrm{mL}$, respectively, which were significantly higher than those in the PE group, i.e. $10.15,7.34$, and $11.96 \mu \mathrm{mol} / \mathrm{mL}$. respectively $(p=0.003)$. The plasma MDA and GSH concentrations can be seen in Table 2.

\section{DISCUSSION}

The age of the subjects in the NP and PE groups was still within the recommended reproductive age range i.e. 20 to 35 years. In the present study there was a tendency for preeclampsia to occur at a higher age than 35 years. At the age above 35 years, there is cellular degeneration causing structural and functional vascular changes so that the subjects are more susceptible to preeclampsia. ${ }^{(4,17)}$ Our study results agree with those of the study by Lamminpaa et al. ${ }^{(17)}$ in Finland, who state that pregnant women of higher age ( $>35$ years) have a 1.5-fold greater tendency to suffer from preeclampsia as compared with pregnant women who are under 35 years of age. Lisonkova and Joseph state in their study that extreme age of women ( $<20$ years or $>35$ years) is associated with the incidence of preeclampsia. ${ }^{(18)}$ In our study, we found that preeclampsia occurred more frequently at a gestational age nearing full term. This finding is in line with the study of Lisonkova and Joseph, who concluded that $>80 \%$ of preeclampsia cases were late onsetpreeclampsia (LOP). ${ }^{(18)}$ The majority of preeclampsia cases do occur near full term, but around $10 \%$ of cases occur before the $34^{\text {th }}$ week of gestation. Early-onset preeclampsia (EOP) is PE occurring before the $34^{\text {th }}$ week of gestation, whereas LOP occurs at or after the $34^{\text {th }}$ week of gestation. ${ }^{(4,19)}$ Increased age of gestation results in increased nutritional demands by the fetus and hemodynamic changes in the mother. This may lead to vascular resistance so increasing the probability of placental hypoxia. Advanced placental hypoxia causes the release of many toxic substances so that preeclampsia occurs. ${ }^{(18,19)}$ Our study shows that there were more multipara in the PE group than in the NP group. Preeclampsia tends to occur in nullipara and primipara rather than in multipara, because in the first pregnancy the formation of antibodies against placental antigens is incomplete so that the implantation of trophoblasts into the uterus is incomplete. ${ }^{(4,20)}$ These results are in line with the study by Paré et al., ${ }^{(20)}$ who state that multiparity is a risk factor for preeclampsia.

In our study, the median plasma MDA concentration in the preeclampsia group was significantly higher than in the normal pregnancy group. The study carried out by Bakacak et al. ${ }^{(21)}$ in Turkey revealed a median plasma MDA concentration that did not differ much from results of the present study, where the median plasma MDA concentration in the preeclamptic pregnancy group was found to be higher than that of the group with normal pregnancies. Consistent results were shown in the study of Subakir et al. ${ }^{(22)}$ who state that plasma MDA concentration in patients with preeclampsia is significantly higher as compared with the control group. Other studies carried out by Chandra et al. ${ }^{(11)}$ and Rafeeinia et al. ${ }^{(23)}$ also show similar 
results, i.e. mean plasma MDA concentration in patients with severe preeclampsia turns out to be significantly different from the mean plasma MDA concentration in normal pregnant women. However, different results were shown by Bowen et al. ${ }^{(15)}$ who state that there were no increases in lipid peroxidation products (MDA) in women with preeclampsia and eclampsia as compared with normal pregnant women.

The oxidative stress underlying the occurrence of systemic inflammation in patients with preeclampsia indicates that there is an imbalance between free radicals and the antioxidant defense mechanism in the course of pregnancy. ${ }^{(6,19)}$

The median plasma GSH concentration in the preeclampsia group was significantly lower than that in the group with normal pregnancy, indicating that there is more extensive oxidative stress in preeclamptic pregnancy. Reactive oxygen species cause decreases in antioxidants in the cells. ${ }^{(12,17)}$ Similar results were shown in the study of Atamer et al. ${ }^{(24)}$ who state that lipid peroxides are significantly increased in PE while antioxidants are significantly decreased. However, different results were shown in the study by Dordević et al. ${ }^{(16)}$ showing that there is no difference in antioxidant concentration between normal pregnant women and women with preeclampsia. In pregnancies complicated with preeclampsia, the antioxidant glutathione (GSH) concentration decreases. Oxidative stress may change the GSH to glutathione disulfide, oxidized glutathione (GSSG) ratio, causing a shift of the GSSG reduction-oxidation buffer towards GSH. In severe preeclampsia there is a decrease in the GSH/GSSG ratio used to neutralize the increased MDA concentration. ${ }^{(10-12)}$

The placenta is known to be the main site of lipid peroxide production in patients with preeclampsia. The hydroxyl radical, the most prevalent radical found, is a very effective substance to effect peroxidation of the plasma membrane of various structures that are rich in the double-bonds of polyunsaturated fatty acids
(PUFAs). ${ }^{(6,7)}$ Preeclampsia is a secondary systemic inflammation due to oxidative stress in the placenta, and its occurrence is associated with remodeling failure of the spiral arteries. Oxidative stress occurring in patients with preeclampsia is probably due to ischemiareperfusion injury in the placenta, that subsequently leads to release of various placental factors into the systemic circulation and ultimately induces the clinical manifestations of preeclampsia. Immediately after the occurrence of reperfusion injury in the placenta, the blood flow becomes adequate again and causes the release of various cytokines and other proinflammatory factors and reactive oxygen species (ROS) particularly superoxides in very large amounts. ROS, in this case superoxides, are extremely reactive and hazardous substances, where ROS may start a lipid oxidation chain reaction that forms more free radicals, and causes the lipid peroxidation process to becomme more extensive. ${ }^{(6,7)}$ Another source of potential oxidative damage in patients with preeclampsia is the release of autoantibodies against the angiotensin receptor (AT1). These autoantibodies stimulate NADPH oxidase, subsequently causing increased production of ROS. In addition, the placenta is also rich in macrophages, that may facilitate the overproduction of local free radicals in the placenta, such as reactive chlorine species (RClS). ${ }^{(6-8)}$

In patients with preeclampsia placental angiogenc activity is significantly lower than in the placenta of normal pregnancy. ${ }^{(6,18)}$ Other studies are similar, as shown by the significant decreases in the mean value of endogenous antioxidants such as GSH, superoxide dismutase, and glutathione peroxidase in preeclampsia cases as compared with normotensive pregnant women. ${ }^{(25)}$

The significant difference between plasma MDA and GSH concentration in preeclampsia and normal pregnant women shows the potential of using MDA and GSH for early detection of 
preeclamptic pregnancy so that early intervention may be performed to prevent preeclampsia or the manifestation of complications. In addition, antioxidant therapy or a high-antioxidant diet may be given to pregnant women at high risk for preeclampsia. One of the limitations of this study is the cross sectional research design, so that the study cannot determine any cause-and-effect association. Further studies should be conducted of a prospective design, such as a cohort design. In addition, in this study there was no controlling for variables that possibly play a role in the pathophysiology of preeclampsia. There is a need to carry out studies involving diet, nutritional status, family history, history of pregnancy and other risk factors that may cause preeclampsia, to determine the possible MDA and GSH concentrations that may be used as marker for the appropriate evaluation of the risk factors of preeclampsia.

\section{CONCLUSIONS}

The group of pregnancies with preeclampsia has a higher MDA concentration and a lower GSH concentration as compared with the group with normal pregnancies. There is clear evidence for a key role of oxidative stress in preeclampsia.

\section{CONFLICT OF INTEREST}

All authors have no conflict of interest in this study.

\section{ACKNOWLEDGEMENT}

We express our gratitude to the Dean of the Faculty of Medicine, Sriwijaya University (FK Unsri) who provided the funds for the study in the form of a research grant for lecturers at FK Unsri. Thanks are also due to Dr. dr. Hj. Aryani Azis, Sp.OG(K) who facilitated the establishment of diagnoses and collection of samples at Muhammadiyah Palembang Hospital.

\section{CONTRIBUTORS}

S contributed to drafting of the manuscript. S, MEPAF, NWA and SS contributed to data acquisition, analysis and/or interpretation. S contributed to revising the manuscript critically for important intellectual content. All authors read and approved the final manuscript.

\section{REFERENCES}

1. World Health Organization. Maternal mortality. Geneva: World Health Organization;2015.

2. Statistics Indonesia, National Population and Family Planning Board, Kementerian Kesehatan, and ICF International. Indonesia demographic and health survey 2012. Jakarta, Indonesia: BPS, BKKBN, Kemenkes, and ICF International;2013.

3. Say L, Chou D, Gemmill A, et al. Global causes of maternal death: a WHO systematic analysis. The Lancet Global Health 2014;2:323-33. doi: 10.1016/ S2214-109X(14)70227-X.

4. Cunningham FG, Gant NF, Leveno KJ, et al. Obstetri Williams. edisi ke-23. Jakarta: EGC;2010.

5. Hutabarat RA, Suparman E, Fagey W. Karakteristik pasien dengan preeklampsia di RSUP Prof. Dr. R. D. Kandou Manado. eCl2016;4: 31-5.

6. Sánchez-Aranguren LC, Prada CE, Riaño-Medina $\mathrm{CE}$, et al. Endothelial dysfunction and preeclampsia: role of oxidative stress. Front Physiol 2014;5:1-11. doi: 10.3389/fphys.2014. 00372.

7. Hung J. Oxidative stress and antioxidants in preeclampsia. J Chin Med Assoc 2007; 70:430-2.

8. Niki E. Lipid peroxidation: physiological levels and dual biological effects. Free Radic Biol Med 2009;47:469-84.

9. Cencioni C, Spallotta F, Martelli F, et al. Oxidative stress and epigenetic regulation in ageing and age-related diseases. Int J Mol Sci 2013;14:1764363.

10. Marbut MM, Majeed MB, Rahim SM, et al. Estimation of malondialdehyde as oxidative factor and glutathione as early detectors of hypertensive pregnant women. Tikrit Med J 2009; 15: 63-9.

11. Chandra S, Widodo MA, Suwarto S, et al. Kadar MDA dan rasio GSH/GSSH pada kehamilan normal, preeklampsia berat dan eklampsia di Malang. JKB 2007;23:35-39.

12. Suhail M, Suhail MZ, Khan H. Alterations in antioxidant and prooxidant balance in 
preeclampsia - impact on erythrocyte osmotic fragility. Biochem Med 2008;18:331-41.

13. Sayyed A, Sontakke A. Study of lipid peroxidation and antioxidant status in preeclampsia. JKIMSU 2013;2:69-76.

14. Genc H, Uzun H, Benian A, et al. Evaluation of oxidative stress markers infirst trimester for assessment of preeclampsia risk. Arch Gynecol Obstet 2011;284:1367-73.

15. Bowen RS, Moodley J, Dutton MF, et al. Oxidative stress in pre-eclampsia. Acta Obstet Gynecol Scand 2001;80:719-25.

16. Dordevic NZ, Babic GM, Markovic SD, et al. Oxidative stress and changes in antioxidative defense system in erythrocytes of preeclampsia in women. Reprod Toxicol 2008;25:213-8.

17. Lamminpaa R, Vehvilainen-Julkunen K, Gissler M, et al. S. Preeclampsia complicated by advanced maternalage: a registry-based study on primiparous women in Finland 1997-2008. BMC Pregnancy Childbirth 2012;12:1-5. doi: 10.3389/ fphys.2014.00372.

18. Lisonkova $\mathrm{S}$, Joseph $\mathrm{KS}$. Incidence of preeclampsia: risk factors and outcomes associated with early-versus late-onset disease. Am J Obstet Gynecol 2013;209:1-12.

19. Valensise H, Vasapollo B, Gagliardi G, et al. Early and late preeclampsia: two different maternal hemodynamic states in the latent phase of the disease. Hypertension 2008;52:873-80.
20. Pare ES, Parry TF, McElrath D, et al. Clinical risk factors for preeclampsia in the $21^{\text {st }}$ century. Obstet Gynecol 2014;124:763-70.

21. Bakacak M, Kylync M, Serin S, et al. Changes in copper, zinc, and malondialdehyde levels and superoxide dismutase activities in pre-eclamptic pregnancies. Med Sci Monit 2015;21:2414-20.

22. Subakir SB, Santosa DIS, Arleni. Kadar MDAdan HSP 70 pada plasenta penderita preeklampsia. Makara Kesehatan 2008;12:93-5.

23. Rafeeinia A, TabandehA, Khajeniazi S, et al. Serum copper, zinc and lipid peroxidation in pregnant women with preeclampsia in Gorgan. Open Biochem J 2014;8:83-8.

24. Atamer Y, Kocyigit Y, Yokus B, et al. Lipid peroxidation, antioxidant defense, status of trace metals and leptin levels in preeclampsia. Eur J Obstet Gynecol Reprod Biol 2005;1 19:60-6.

25. Ozkaya O, Mekin S, Hakan K. Serum malondialdehyde, erythrocyte glutation peroxidase, and erythrocyte superoxide dismutase levels in woman with early spontaneous abortion accompanied by vaginal bleeding. Med Sci Monit 2008;14:47-51. 